\title{
Outside, en pandemia
}

\author{
(4) Eva Bidegain \\ Investigadora independiente \\ Hanna Quevedo \\ Fotografías
}

El 24 de marzo de 2020, el presidente anunciaba que México ingresaba a la fase 2 de la pandemia y decretaba el cese de actividades que ahora se definían "no esenciales". Los residentes debían encerrarse en sus casas, confiar que los servicios de salud biomédicos dieran abasto y que la ciencia hallase la cura. Las redes sociales se llenaron de cartografías, de infografías, de sospecha. Limitaban la movilidad en medio del individualismo. Cuando la gran mayoría de los amigos, vecinos, colegas pararon, se encerraron, se aislaron, otros, en cambio, salimos fuera. Buscábamos cómo sobrevivir, anhelábamos la comunidad. En las mayores disyuntivas de la vida, moverse es el camino. Era también aislarse de las redes sociales, de la economía formal, de los controles migratorios, de los escáneres de los aeropuertos, de la cómoda cama, de la mesa servida, de la rutina.

Esta es la crónica de algunos de los que nos estábamos moviendo en medio de una pandemia. Es la crónica de un viaje con nómades y pobladores rurales del interior profundo de California, Estados Unidos.

Estamos en agosto. Estados Unidos declara que lleva 4 millones 713 mil diagnósticos positivos y más de 155 mil muertos por COVID19. En el mundo, 18 millones son clasificados casos nuevos y 692 mil muertes por esta enfermedad. Luego de Nueva York, el estado de California, particularmente el sur, concentra la mayor cantidad de casos nuevos. Cruzando la frontera, los estados norteños mexicanos de Baja California y Chihuahua tienen las tasas más altas de muertes de todo el país. Estados Unidos cierra las fronteras terrestres el 21 de marzo, pero mantiene los ingresos por vuelos internacionales.

Estamos en agosto del 2020. Llegamos a una ciudad de Los Ángeles desierta, con locales cerrados y sin estridencia. Decidimos ir tierra adentro y conocer los pocos parques nacionales que permanecían abiertos, acampar, rodar. Hay tiempo de sobra, es un tiempo excepcional. En el trayecto, carteles panorámicos piden en tono nacionalista detener el COVID19 restringiendo la movilidad. Los consumidores en los supermercados mantienen distancia entre góndolas y los drive-thu están que explotan. 
Atravesamos paisajes de desiertos y mar. Tierra adentro, ingresamos rutas rodeadas de pinos, oliendo a pinos. Casas de dos plantas, de madera, muchas escondidas detrás de portones verde olivo con la advertencia de propiedad privada. Ha cambiado el color de piel y la edad de los lugareños. El periódico The Union anuncia servicios de salud y seguros de vida a lectores mayores de 50 años.

En las tiendas de Goodwill, Target o Walmart no hallamos tienda pequeña para acampar. Los vendedores dicen que las importaciones de China se restringieron con la pandemia. Parece como si todo el mundo estuviera aislándose outdoor. La región al norte de Sacramento, entre Yuba y Chico, es una zona de valles y montañas, territorio de osos y venados que se esconden entre coníferas. Nevada City conserva la estética de una ciudad del far west cinematográfico con el Banco en la esquina, la oficina de correos y las cantinas, hoy convertidas en discretos restaurantes de comida orgánica o boutiques. En las montañas, a unos $12 \mathrm{~km}$ de este poblado, el único transporte público está suspendido por la pandemia. ¿Cómo harán los adultos mayores, o quienes no cuentan con vehículo propio para bajar a la ciudad por una emergencia médica? Una pregunta que viene de haber vivido en las periferias de las ciudades y pueblos de Argentina. Sin embargo, los que viven en estas montañas conducen trucks. Fuera de los caminos principales, el resto es ripio, polvo o lodo. No hay líneas de internet y las señales telefónicas fallan. Perfecto refugio para pasar una pandemia.

\section{California}

El primer best seller de un nativo americano trata sobre las andanzas de un mexicano que emigra por trabajo a California. Luego de que son asesinadas su mujer y hermano, se hace forajido y justiciero. La serie "El zorro" fue su adaptación a la televisión y al cine. Llegamos a la zona que lleva el nombre de este escritor cherokee -John Ridge-, que sentía antipatía a otros pueblos indígenas y contó la explotación de los migrantes en la época de bonanzas.

La fiebre del oro marcó a California. Le imprimió la primera oleada de nómades entre 1848 y 1855 . Llegaron de Oregon, Islas Sandwich, Chile, Sonora, Perú, de Francia, de Australia, de Génova. Más de 300 mil personas llegaron. San Francisco sumó en esa época, a los 200 residentes casi 36 mil y para 1850 ya era estado independizado de México y anexado a los demás estados de la Unión. Junto al oro, llegaron caminos, rieles, agricultura y extracción de agua dulce. La forma de pala de pico de las señales de las rutas estatales recuerda la leyenda. Su escudo donde la Fortuna grita ${ }_{i} E u r e k a ! ~ Y$ sigue siendo un imán para muchos.

El aire seco, las montañas, el buen clima, el sol fue considerado ideal para respirar y durante el siglo 19 hasta mediados del 20, California fue recomendado para descansar y para tratar la tuberculosis pulmonar. Más tarde, llegó la psicodelia del movimiento hippie, la aventura de las carreteras, los atardeceres soleados, la industria del cine y la música, el valle de las empresas informáticas que dominan el siglo 21. El imaginario de California y su color ocre, sinónimo de surfers, libertad, juventud y abundancia se expande más allá de las fronteras, llega en playeras, en videoclips, en las pantallas. Joan Didion se fue hacia San Francisco para poder verlo todo en 1968 y escribió que "una persona de cada treinta y ocho viven en una caravan" y que esta gente "intenta encontrar un nuevo estilo de vida" (Didion, 2019).

Nuevo estilo y reinventarse una vida sigue atrayendo a esta zona de los valles interiores, en plena pandemia, a jóvenes de entre 23 a 40 años procedentes de otros estados de Estados Unidos, de Canadá, de América Latina y del sur de Europa para trabajar en las 
temporadas de las granjas de marihuana, viñedos, hortalizas y pizca de frutas. Mónica, una mujer sexagenaria, de tez blanca arrugada y pelo gris que reside en la zona hace más de 40 años, nos dice que están acostumbrados de ver llegar los contingentes de jóvenes cada año. Asegura que no molesta, más bien, renuevan la zona, consumen. Producen.

California es una de las economías más pujantes de Estados Unidos y se promociona como el oasis de la agricultura orgánica. En cualquier tienda aislada en medio de las montañas, encontramos productos que se venden como "orgánicos": hortalizas sin pesticidas, huevos, lácteos, kombuchas, ghee, tinturas, alimentos based plant, cigarros de tabaco orgánico, derivados de marihuana y otras plantas medicinales. Los viñedos completan el paisaje del valle, se observan discretos en los caminos vecinales, sin explotación hotelero-gastronómica. El consumo de agua local por parte de la agricultura es mayor que la doméstica en todo el mundo, pero en estas tierras se presiente una especie de ansiedad de la sequía. El fuego alimenta estas pesadillas.

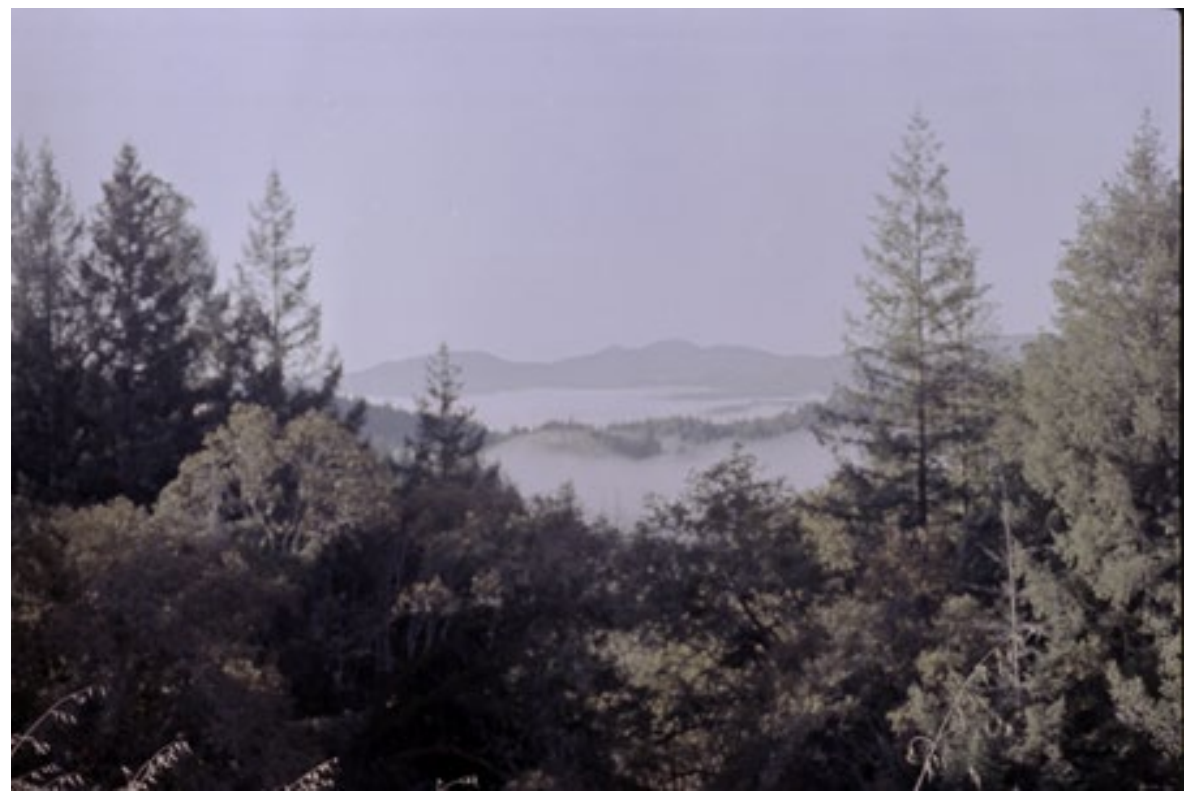

Fotografía de Hanna Quevedo.

\section{Incendios}

Desde 2015 California registra importantes sequías. La temporada de vientos calientes es habitual en las Californias. Viento de Satanás, fue llamado por los evangelizadores españoles cuando las Californias era un vasto territorio anexado al Reino de España. Los vientos calientes, trastornan los ánimos, el polvo lo invade todo. Las cenizas están en el aire. Cada año provocan incendios en la alta y Baja California, y cada año son más devastadores.

Estamos en septiembre, y los bomberos cortan la luz eléctrica y los pueblos cierran comercios, supermercados, licorerías, bancos. Si ya estos pueblos en pandemia parecían el preludio de una inminente tragedia, sin electricidad, la vida en las montañas se vuelve más rudimentaria y aislada. Las gasolineras se llenan de lugareños cargando galones y galones de gasolina para los generadores a diésel que sólo algunos poseen. 
El aire huele a fuego, de día y de noche el cielo es naranja, el humo parece la neblina densa de los días de humedad y frío. Un ambiente raro. Se oyen helicópteros sobrevolar la zona y de boca en boca de los mensajes de texto, viralizan lo que internet y la televisión emiten espectacularmente sobre el avance de los incendios, tema nacional. Hay más preocupación en la voracidad del fuego, por el tiempo de evacuación, por las pérdidas de cultivos y casas, que en la letalidad de un virus que parece estar lejos. Hay más señales y anuncios de evitar hacer fuegos que sobre lavado de manos y gel en los pueblos rurales. Los fuegos parecen sobrevenir, en la noche y durante el día, inquietan los ánimos.

\section{Les nómades}

"Cuando uno es un viajero y un extranjero hay que ser prudente y reservado, de esta manera uno se preserva del mal. Si uno es cortés con los demás, tendrá éxito." (El viajero, Hexagrama 56, I Ching).

Las mujeres que toman los caminos se detienen en los contornos, en los bordes. Aprovechan el tiempo descansando desnudas en la ribera del frío y claro río Yuba tomando sol sobre las grandes rocas, compartiendo cervezas con otros nómades, fumando y cantando melancólicas canciones folk.

Becki, de Indiana, tiene 38 años y hace cinco que viaja en su Subaru 4x4 del año 2000. Viaja y carga lo necesario: colchón, un sleeping, tazas, sus piedras semipreciosas, sus papeles, stickers. Trabaja temporalmente en granjas donde tiene techo y comida, y cuando se acaba el trabajo, se queda en estacionamientos o en hoteles económicos que abundan en los bordes de las ciudades más grandes. Becki trae unos pantalones cargo gastados, una playera negra con una impresión, gastadas y una gorra que dice Namasté. $\mathrm{Y}$ dice que su madre es alemana y su padre norteamericano. Y de ellos, supongo que tiene la piel rosa y los ojos grandes. El chasquido cuando habla, es sureño. Su meta es hacerse su propio terreno, su propia granja y su propia casa. Solitaria, domina el territorio sin usar GPS y ubica donde hay vertientes de agua caliente (hot springs) y de agua dulce potable (springs).

Una mujer de más de 60 años camina descalza por granjas y caminos, y regala horóscopos e invita a su comunidad de viejos hippies de los sesentas que conviven, aunque no son parientes. Kevin, Fran y su novia Alexia, viven en un rancho a $2 \mathrm{~km}$ de la carretera en un rancho regentado por una anciana viuda que subarrienda parte de su terreno a mujeres feministas, que llegaron de Nueva York y Montana, y que están criando solas a hijos pequeños. Son activistas ambientales y seguidores de Bernie Sanders que siembran y consumen marihuana local. No son parientes, son convivientes. Laura de 60 años es amiga de Clive y viven junto a otros amigos en un rancho que compraron recientemente, disponiéndose en motorhomes (trailers) rodeando una casa móvil comunitaria central. Viven de trabajo de voluntariado en el pueblo, reciben ayudas del gobierno federal y venden lo que cultivan en su granja. Detestan a los fanáticos de Trump y son sencillos, serenos. Tampoco son parientes, son convivientes. Son una clase de norteamericanos que no suelen verse en las películas comerciales. Buscan lo mismo que todos, vivir pacíficamente.

Lemmon, de 24 años, viaja con Saraswati, una india de 26 años, que viene a conocer América. Prepara un guisado de arroz con verduras, sentada de cuclillas frente a un fuego y mientras sirve mira a los ojos con detenimiento, como yogui. Ambas están viajando por carreteras hace más de un año, quedando a hacer servicios a cambio de posada. 
Carola, es una italiana cuya meta es colocarse como "grover" en una actividad dominada por varones blancos de mediana edad con la arrogancia emprendedora de los empresarios de Silicon Valley. Desde el 1996 es legal el cultivo de marihuana en California y desde hace menos de 3 años, ya cotiza en la bolsa.

Distintas entre sí, tienen en común que son mujeres que van tejiendo una comunidad, llevando mensajes de cuidado mezclados con autoconocimiento new age y manejo práctico de la economía. No creen en los países donde nacieron y vivieron hasta hace poco, en sus gobiernos. Desconfían de la economía formal. Lo tienen presente, no se olvidan de dónde han salido y eso alimenta el deseo de estar aquí, buscando cómo sobrevivir, moviéndose.

Somos una diáspora tentacular, en medio de una pandemia. Afuera los negocios digitales estaban tomando fuerza y las criptomonedas subiendo de valor, amenazando la economía del dinero Fiat. Aquí, en las montañas, crecía y se cultivaba la creencia en la tierra, en los tiempos de las estaciones, en la fuerza de trabajo, en las relaciones cara a cara y en la economía no financiada. Algunos nómades aspiran ahorrar y comprar terreno y construirse casa propia. Porque ser nómade no implica no tener raíces. El poder del nómade es su movilidad. Algunos sólo quieren viajar un tiempo por playas y selvas. Otros, aprovechan estar aquí, para acceder a tecnologías como computadoras, bocinas, celulares, que en los países de donde salieron, cuestan una fortuna. Y están los que se proponen vivir en casas móviles como estilo de vida. Hay distintos tipos de nómades. Sleeping bags, mochilas que desbordan, hilos cordeles zapatos gastados, ropa gastada son sus señas particulares. En movimiento, uno aprende a llevar lo necesario y algunos tesoros como cartas, plumas, piedras, dibujos. Mecheros, botella de agua y los infaltables cuchillos y gas pimienta, armas de autodefensa de las mujeres que viajamos solas. El tono ocre de las ropas, tatuajes en manos, cabellos sueltos, libres, enredados. El aroma ácido invadiéndolo todo, mezclas de esencias y de fluidos, de aguas dulces, de resinas, de tabaco y de mota. Me pregunté viéndolos y viéndome: ¿Arraigar tiene que ver con sedentarismo? ¿El sedentarismo es una forma de habitar de un modo de producir? ¿Es una ideología? ¿Son los nómades marginales por definición? ¿Marginados de qué? Tal vez sea la necesidad de sentirnos vivos, sintiendo lo vivo, la potencia y el vértigo de los caminos.

Estamos en noviembre. Ya empiezan las lluvias y muchos van hacia la costa. Otros se arriman más al norte, a la nieve. No hay nada espectacular en este viaje, pero es especial. Sobre las hojas de un libro, Belle dibuja trazos, una crónica de las siluetas de las personas que va conociendo en el camino. Luce pelo largo, con unas hebras trenzadas. Casi siempre lleva botas o sandalias de viaje. Tiene 23 años, es blanca, delgada, de cara pequeña, con pecas en las mejillas y pelo azabache. Usa pantalones de outdoor, o calzas y tops, todo entre el color negro y café. Estudia artes y de las temporadas de trabajo en las granjas, ahorró para comprar su Van donde puede moverse dónde quiera, llevando su mundo. Su mundo son pinturas, ramas secas, plumas, patchworks, telas con estampados batik. Va aprendiendo a vivir viajando. Aún no sabe dónde irá este invierno, ni dónde estará el año próximo, con o sin pandemia. 


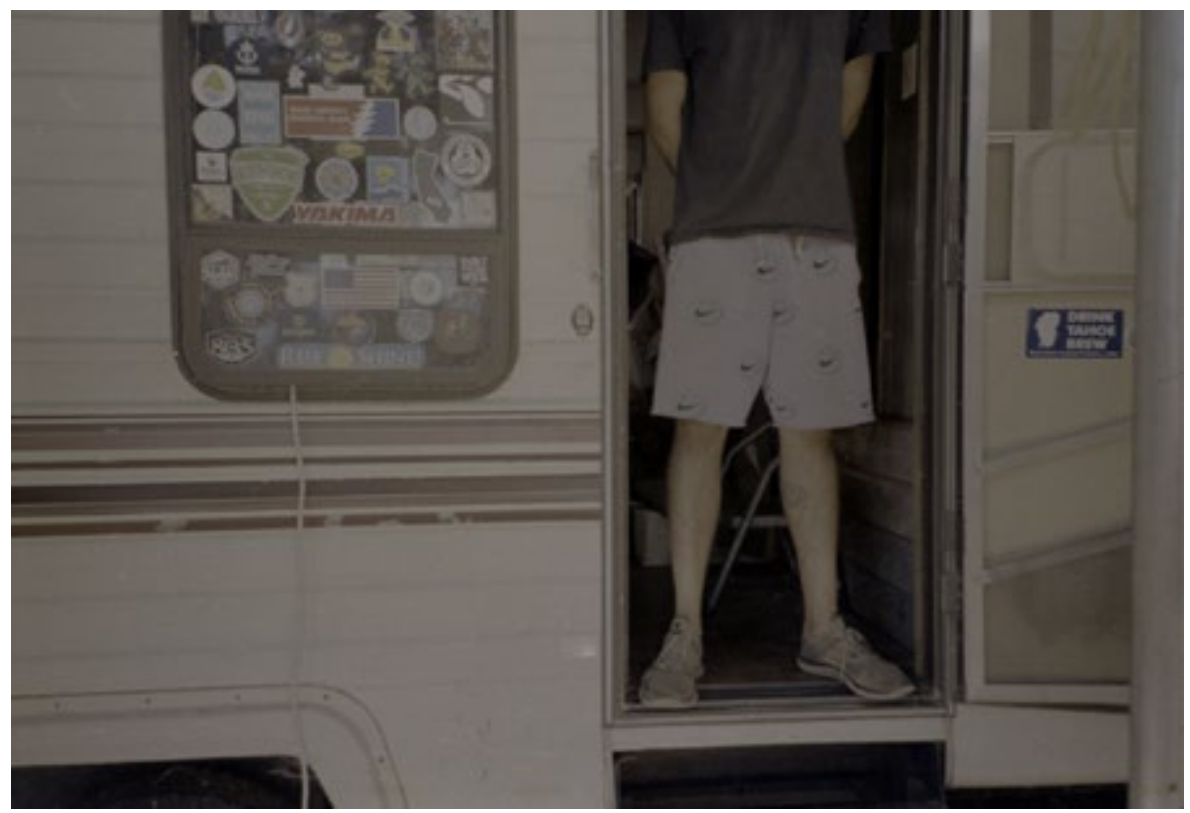

Fotografía de Hanna Quevedo.

\section{Motorhomes}

Estados Unidos es el país con mayor cantidad de carreteras: $6.430 .366 \mathrm{~km}$. Es el tercer país americano que consume más petróleo per cápita, luego de Canadá y Groenlandia. Por menos de 2500 dólares es posible comprar un vehículo cupé, y por 4000 dólares una pequeña van de más de 10 años. Les nómades se mueven en estos vehículos que les permiten subir y bajar caminos de terracería. Hay todo un negocio que se cierne sobre les nómades y su movilidad. En los pueblos entre Sacramento, Chico y Riverside, pululan los intercambios de vehículos de este tipo. Cuanto más lejos de la costa y de la frontera esté el vendedor, más alto será el precio de todo.

A fines de la segunda posguerra, la vivienda comenzó a ser un problema en Estados Unidos. Las casas prefabricadas móviles, los motorhomes y buses escolares amarillos, carros comunes, usados, convertidos en vivienda. Es parte del paisaje e imaginario del sur de California y Texas. Hoy cerca de 20 millones de personas viven en la actualidad en motorhomes. Una nota de prensa de Los Ángeles Times de agosto del 2019 indicaba que California era el estado con mayor cantidad de homeless.

En los pueblos abundan tiendas de segunda mano. Dice Michel Harrington: "En los Estados Unidos resulta más fácil andar decentemente vestido que alojarse o recibir servicio médico en forma decente. Incluso las personas con ingresos terriblemente bajos pueden parecer prósperas" (Harrington, 1962:14).

En el 2018 más de 129 mil personas vivían en la calle. No sabemos cuántos nómades, rodando. No los registran los censos nacionales. 


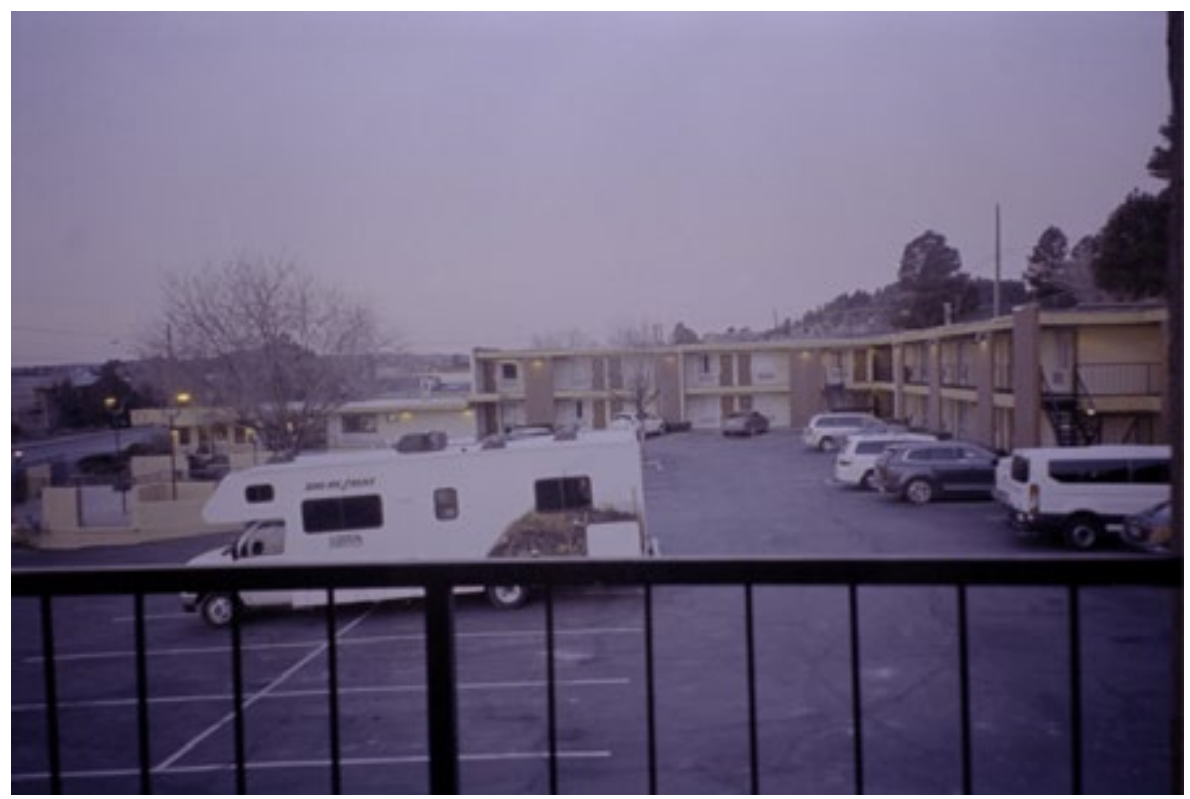

Fotografía de Hanna Quevedo.

\section{El agua}

"El viajero no tiene domicilio fijo, el camino es su hogar. Por eso debe estar atento a ser siempre interiormente justo y firme, a no detenerse sino en los lugares propicios y a tratar solamente con buena gente." (Lü, El viajero, Hexagrama 56, I Ching).

Entre Sacramento y el valle de Nevada hay una serie de Springs donde los pobladores concurren a llenar envases de 20 litros. Como otros spring waters, son sitios de uso comunal de agua fresca gratuita. Allí, los lugareños dejan cajas con ropas, libros, juguetes, verduras y snacks. También se puede hallar lo mismo en los caminos principales, junto a las postas de correo. Cada jueves, voluntarios sonrientes y amables de una Iglesia Comunitaria del pueblo, entregaban cajas de "Food Banks" que contienen verduras frescas, carnes de ave, res, pescado, embutidos, huevos, mantequilla, leche, pan, frutas, snacks, tortillas de maíz, frutas y hortalizas enlatadas. Los centros comunitarios también ofrecen acopio de legumbres, papas y avena. E iniciando la temporada de lluvias y frío, ofrecen calefacción, catres de aluminio, cobijas, sábanas blancas, baño, un tazón de sopa, un desayuno.

Estamos en noviembre. Nos tocan días de lluvias torrenciales y frío. Dormimos en los estacionamientos en el pueblo, junto a otros carros y motorhomes. También nos reciben en uno de tantos centros comunitarios, atendido por una joven pareja de voluntarios. No hay nada más amable que un cuarto seco, cálido, donde dejar secar la ropa, un caldo a la noche y café. Un refugio.

\section{Respirar}

El yoga y los símbolos hindú budistas están por todos lados, y hay comunidades que viven en granjas dedicadas a una vida más lenta, consumiendo vegano y haciendo cantes y posturas yóguicas. 
En la India consideran el cannabis una ofrenda de los dioses. Brotó cuando Amrita cayó de los cielos. Néctar divino, consagrado a Shiva y elixir favorito de Indra. Los sadhus, de pelo largo y mirada hacia dentro, consagran su vida a Shiva, practicando la meditación, yoga y consumiendo chara (hachís pulverizado a mano) o la ganjah. Dicen que tienen larga vida, salud y visiones.

Bronco, es delgado, tiene barba y pelos desordenados del color de maíz y canta mantras a Shiva mientras cultiva sus propias plantas. Cada mañana, luego de su rutina de yoga, fumaba su chillum, que adoptó luego de varios viajes a la India. Se trata de un embudo estrecho, generalmente de arcilla cocida, y dentro tiene una piedra que actúa de filtro para evitar que el hash caiga al fumar. "Boom Bolenathn!", el primer calado era para la deidad. Los siguientes, para conversar y cantar mantras.

Hongos, mota y ácido, coca, DMT, son de consumo habitual, circulan en los pueblos rurales y en los bares y fiestas privadas -que no se habían suspendido durante toda la pandemia. Aquí no hubo desabasto de alcohol como en el norte de México a inicios de la pandemia.

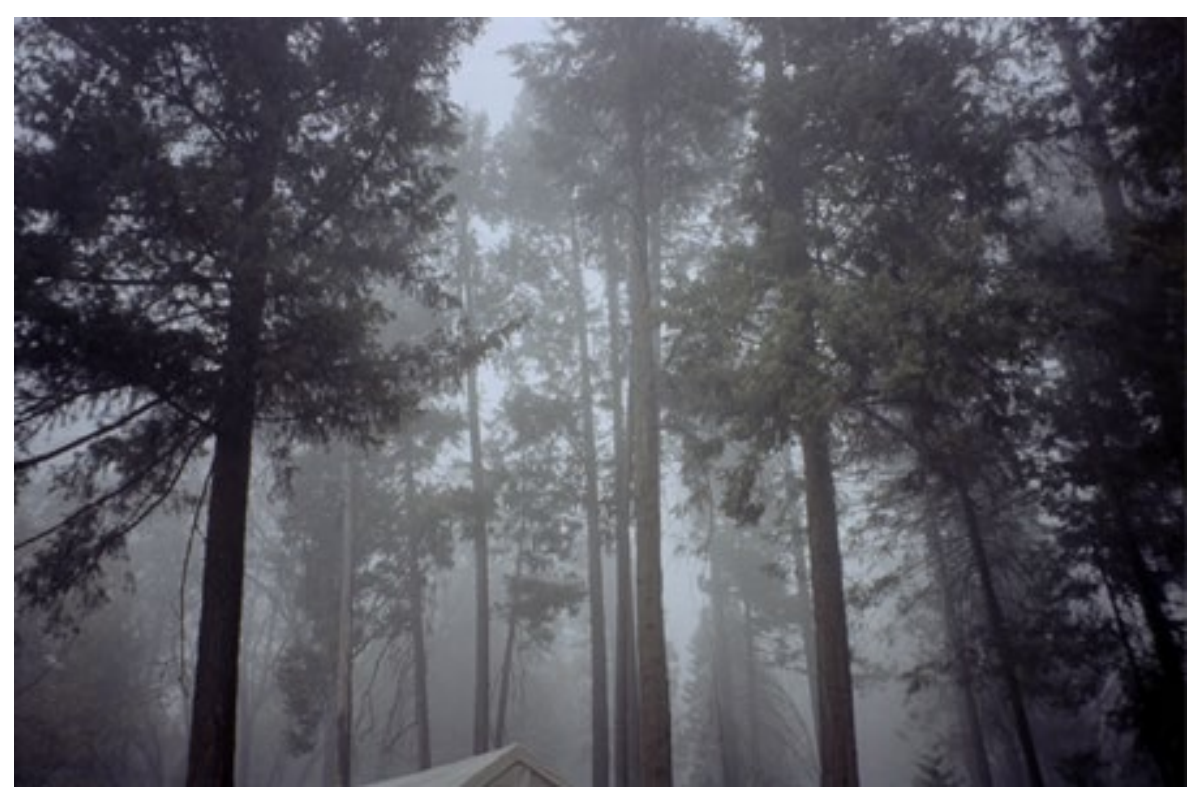

Fotografía de Hanna Quevedo.

\section{El regreso}

Estamos en diciembre. Pasamos brevemente por una desierta y estrafalaria Las Vegas hacia el desierto de Yuma. Atravesamos el Death Valley y el Mojave. En los poblados más cercanos a la frontera, próximos a la Route 66, abundan los "Park CV" que ofrecen duchas, agua caliente, electricidad y depósito para descargar aguas negras por 45 dólares la estancia.

También existen varios spots gratuitos a cielo abierto que están en los mapas de cualquier app con GPS. Las luces de mi Ford wagoneer apenas iluminan el camino del spot. Se insinúan siluetas de vehículos grandes. Son pasadas las 2 de la mañana y afuera hace menos de 5 grados de temperatura. Ya al amanecer, disponiendo la cocinilla para unos mates, divisó la veintena de vehículos desparramados allí. Varones y mujeres blancos, 
de la "tercera edad", en pijamas, como si fuese un barrio residencial de la tercera edad. Todos saludan amablemente. Ninguno de ellos lleva cubrebocas. Jubilados, retirados de las fuerzas militares o sin casa fija, viajan solos o con una mascota en sus motorhomes. Habitan así. Se mueven así.

Estamos más cerca de la frontera con México. Del valle de pinos, resina e incendios, al valle yermo donde crecen por gracia de la industria del agro brócolis, lechugas, espinacas, coles y calabazas en líneas extendidas sobre un suelo cubierto con tierra negra y lona negra. Los jornaleros caminan en cuadrillas, en línea. Retiran inclinados los brotes de lo que no debe crecer, la "maleza". Viven allí nomás, en casas grandes, estilo americano, color crema, a dos aguas, porche y césped, que rentan o han logrado pagar a cuotas, rodeados de extensiones monocromáticas verde olivo oliendo a abono y químicos, bajo un cielo caliente.

Es diciembre. En el sur de California y Arizona se concentran la cantidad de casos de coronavirus. Me dice Estela, una mujer chaparrita, nacida y criada en la península de Baja California en México que hay días que arden los ojos, o la piel. Que se comparten tamales entre los compañeros como ibuprofenos con hierro para aguantar. Pensando con ella y en su persistencia de residir de manera sedentaria para ganar dólares que valen más cruzando la frontera, pensé en mí, en todos los que nos seguimos moviendo cuando las rutinas fueron detenidas. Pensé en nosotros dentro de la consolidación del neoliberalismo, su flexibilidad laboral, su intensificación laboral antes de la pandemia, treinta, veinte años atrás, cuando algunas de las compañeras de camino ni habían nacido. Pensé en nosotros, una generación crecida en medio de las consecuencias del trabajo precario. Cansados, ya estábamos aislados, aunque nos ocuparan tenernos hiperconectados. No había tiempo para conocernos y cultivar las relaciones genuinas. No había tiempo para aprender cosas vitales como el cuidado, sentir el cuerpo, el valor de la comunidad, la vida más allá de lo humano, el funcionamiento de la economía real. Cosas simples y vitales que aprendemos en movimiento, incluso en medio de una pandemia. 


\section{Q Bibliografía}

»Didion, J. (2019) Arrastrarse hacia Belén (1968). En: Los que sueñan el sueño dorado. Random House. España.

» Harrington, M. (1962). La cultura de la pobreza en los Estados Unidos. México: FCE.

\section{Eva Bidegain / evabidegain@gmail.com}

Doctora en Antropología Social. Etnógrafa, documentalista y cronista. Le interesan temas de salud y enfermedad, imaginarios y formas de habitar alternativos. Compila material sobre movilidad y formas de habitar en su blog personal: https://etnografiahabitar.blogspot.com. Desde el 2015 reside en México.

\section{Hanna Quevedo / https://hannaquevedo.com}

Fotógrafa y docente. Ha exhibido y obtenido premios de fotografía en festivales de España, EUA y México, países entre los que vive y trabaja actualmente. Mayormente ha ejercido como fotoperiodista y, en la última década, se ha dedicado también a desarrollar dispositivos de fotovoz. Autora de Dessert First!, editado por Hydra/Inframundo (CDMX, México) and Burn Barrel Press (Nueva Orleans, EEUU). 